\title{
: \\ Neutralidade da ciência, desencantamento do mundo e controle da natureza
}

\author{
Marcos Barbosa de Oliveira
}

\begin{abstract}
苗
RESUMO

O objetivo deste ensaio é explorar o auto-controle como alternativa às práticas de controle ou dominação da natureza, no contexto dos problemas ecológicos, primeiro pelos indivíduos, depois pela sociedade e, por fim, pela ciência. O ponto de partida é uma análise em três componentes da tese da neutralidade da ciência, uma das quais - a tese da neutralidade factual - reflete o caráter puramente descritivo das proposições científicas e tem uma estreita ligação com o controle da natureza. A supervalorização do controle da natureza característica da modernidade, por sua vez, é vista como parte das causas dos problemas ecológicos, cuja superação demonstra a necessidade da adoção do auto-controle, não apenas pelos indivíduos, mas ainda mais crucialmente pela sociedade, sendo o auto-controle social incompatível com a dinâmica do sistema capitalista. Na seção final, identifica-se o auto-controle no domínio da ciência com a autonomia, mostra-se como a reivindicação tradicional da autonomia, baseada na neutralidade, não mais se sustenta, em virtude dos processos de mercantilização a que a ciência é submetida. Como conclusão, propõe-se uma modalidade alternativa de autonomia, em que a ciência é colocada não acima, mas ao lado de outras formas de conhecimento e outras instituições sociais.
\end{abstract}

Palavras-Ghave $\bullet$ Neutralidade. Desencantamento do mundo. Controle da natureza.

Dominação da natureza. Eco-socialismo. Auto-controle. Autonomia. Lacey.

\section{INTRODUÇÃO: A TESE DA NEUTRALIDADE DA GIÊNGIA}

As reflexões expostas a seguir nasceram de um programa de estudos centrado na questão da neutralidade da ciência e têm,como ponto de partida,o esquema conceitual estruturado ao longo desses estudos, que apresentamos de forma sumária nesta introdução.

A neutralidade implícita na tese de que a ciência é - ou não é - neutra é evidentemente uma neutralidade em relação a valores; prova disso é que em muitos contextos, em lugar de "a ciência é neutra" se diz sinonimamente "a ciência é livre de valores".

$1 \mathrm{Na}$ filosofia de Hugh Lacey, à qual voltaremos a referir, o tema central, grosso modo equivalente ao programa de estudos em pauta, é designado por essa expressão; no título do principal livro onde é exposta - Is science value free?: values and scientific understanding (Lacey, 1999), Lacey também emprega a expressão "neutralidade da ciência”, porém com um sentido diferente, mais restrito do que o aqui adotado. 
Os valores neste contexto são os valores sociais, definidos como aqueles que podem variar de cultura para cultura, de época para época, ao longo da história de cada cultura, e de grupo social para grupo social, nas sociedades marcadas por contradições internas. Já nesse nível de generalidade podem ser indicadas duas implicações fundamentais da tese. Ao isolar a ciência da esfera valorativa, a tese da neutralidade, primeiro, coloca a ciência fora do alcance de questionamentos em termos de valores sociais - sendo essa a implicação mais relevante de um ponto de vista interno à cultura ocidental - e, segundo, permite que a ciência seja posta como um valor universal - o que é relevante especialmente no que se refere às relações da cultura ocidental com outras culturas.

Há três domínios nas práticas científicas em que os valores sociais podem estar presentes. O primeiro corresponde ao momento da seleção dos fenômenos a serem investigados, ou dos problemas a serem tratados. Desta escolha depende o direcionamento da pesquisa e, conseqüentemente, o avanço da ciência. O segundo corresponde ao momento da escolha entre as teorias propostas para explicar os fenômenos ou resolver os problemas, sendo o conjunto de normas que norteiam essa escolha identificado com a metodologia científica, no sentido em que essa expressão é normalmente usada na filosofia da ciência. E o terceiro é o domínio do próprio conteúdo das proposições científicas. A cada um desses domínios corresponde uma faceta, ou sub-tese, da tese da neutralidade, negando cada uma a presença de valores no respectivo domínio, a saber:

1 Tese da neutralidade temática: a ciência é neutra porque o direcionamento da pesquisa científica, isto é, a escolha dos temas e problemas a serem investigados, responde apenas ao interesse em desenvolver o conhecimento como um fim em si mesmo.

2 Tese da neutralidade metodológica: a ciência é neutra porque procede de acordo com o método científico, segundo o qual a escolha racional entre as teorias não deve envolver, e de maneira geral não tem envolvido, valores sociais.

3 Tese da neutralidade factual: a ciência é neutra porque não envolve juízos de valor; ela apenas descreve a realidade, sem fazer prescrições; suas proposições são puramente factuais.

Apesar de poderem e deverem ser distinguidas, essas teses não são independentes umas das outras. Grosso modo, elas se reforçam mutuamente, além de em muitos pontos se articularem de formas logicamente mais precisas. Se em um patamar excluem da ciência os valores sociais, em outro elas funcionam também como valores, no sentido de que a neutralidade não é simplesmente dada, mas corresponde a uma aspiração da ciência, que envolve esforço para que se realize. Tais esforços se dão não ape- 
nas no interior da prática científica, mas envolvem as relações da ciência com a sociedade e, nesse terreno, eles adquirem o caráter de uma reivindicação - a reivindicação de autonomia, como veremos a seguir.

Passemos agora à análise do significado da tese da neutralidade factual.

\section{Desencantamento do mundo, dominação e gontrole da natureza}

A factualidade, afirmada pela tese da neutralidade factual, é um dos traços mais marcantes da ciência moderna; e a separação entre fatos e valores que essa tese pressupõe impregnou profundamente toda a cultura ocidental. Tal separação, como se sabe, não prevalecia na visão aristotélica de mundo, e o processo que a instaurou constitui um dos aspectos mais importantes da Revolução Científica, que deu origem à ciência moderna.

$\mathrm{O}$ conceito de desencantamento do mundo tem em Weber um significado bastante complexo, comportando muitas variantes e nuanças (cf. Pierucci, 2003). Nesta exposição, vamos usar o termo em um sentido mais preciso e restrito, para designar o processo histórico de separação de fatos e valores, do qual resultou o caráter factual da ciência moderna.

A ciência desencantada, neste sentido, afeta duplamente as relações do homem com a natureza: ela não só legitima a postura de dominação, mas também fornece, através da tecnologia, os meios para ampliar e tornar a dominação mais eficiente. Se a maneira correta de ver a natureza é a da ciência moderna, e se as proposições desta são puramente factuais, então a natureza se reduz a uma coleção de fatos, desprovida de valor intrínseco, restando apenas o valor instrumental para nós. Sendo assim, não há restrição ética a que a dominemos, tratando-a da maneira que nos aprouver para satisfazer nossas necessidades e desejos, de forma cada vez mais ampla e eficiente graças à aplicação tecnológica do próprio conhecimento científico.

Um autor que expressou eloqüentemente essa dupla conexão foi Marx, numa passagem dos Grundrisse, na qual, associando o desencantamento do mundo e a dominação da natureza ao capitalismo, afirma:

[Com a produção fundada no capital], pela primeira vez a natureza se torna puramente um objeto para a humanidade, puramente uma questão de utilidade; ela deixa de ser reconhecida como um poder em si mesma; e a descoberta teórica de suas leis autônomas aparece meramente como um estratagema para subjugá-la às necessidades humanas, quer como objeto de consumo, quer como meio de produção (Marx, 1973, p. 4,0). 
Em uma análise mais detida, a ligação da ciência moderna com a dominação da natureza manifesta-se no caráter experimental de sua metodologia, uma vez que tanto experimentos como dispositivos tecnológicos são formas de dominação da natureza. O que muda é o objetivo: no caso dos experimentos, obrigar a natureza a revelar seus segredos, as leis que regem seus fenômenos; no caso da tecnologia, obrigá-la, por assim dizer, a trabalhar para nós. Assim, na medida em que a ciência, mesmo quando concebida como ciência pura, elege o teste experimental como critério de validação de teorias, ela já exibe a marca de suas afinidades com a tecnologia e seu comprometimento com a dominação da natureza.

Considerada por si só, a idéia de dominação da natureza tem uma longa história, que remonta pelo menos à Bíblia. Mais precisamente, de acordo com algumas interpretações, passagens do versículo primeiro do Gênesis, tal como aquela onde se lê:

Deus disse: "Façamos o homem à nossa imagem, como nossa semelhança, e que eles dominem sobre os peixes do mar, as aves do céu, os animais domésticos, todas as feras e todos os répteis que rastejam sobre a terra".

Um tratamento muito completo e competente do tema encontra-se no livro de William Leiss, The domination of nature (Leiss, 1974). Mas, para nossos propósitos, é desnecessário entrar em detalhes. Diremos apenas que, na modernidade, já associada à ciência e à tecnologia, a dominação da natureza é afirmada explícita e enfaticamente como algo positivo, algo que engrandece o homem (especialmente, entre os pioneiros da ciência moderna, como Bacon, por exemplo), e que, na perspectiva crítica, destacam-se, no século xx, os pensadores da Escola de Frankfurt.

Embora as posições defendidas nesta reflexão tenham muitos pontos em comum com as dos frankfurtianos, vamos tomar como ponto de partida das considerações que se seguem não o conceito de dominação da natureza, mas o conceito afim de controle da natureza, tal como mobilizado por Hugh Lacey. O conceito de controle da natureza é uma peça-chave na estrutura de idéias que constitui a filosofia da ciência de Lacey. Comparado com o conceito de dominação da natureza dos frankfurtianos é, por um lado, mais matizado, por outro, definido com maior precisão. É mais matizado porque, para Lacey, a prática de controle dos objetos naturais é parte da natureza humana, estando presente, e sendo valorizada, sob certas condições, em todas as culturas (cf. Lacey, 1999, p. 111). Esta é uma das razões que leva nosso autor a preferir o termo "controle", menos carregado valorativamente que o termo "dominação" dos frankfurtianos. De nossa parte, temos também outras razões - que ficarão evidentes a seguir - para optar por "controle" em vez de "dominação". 
O controle é definido por Lacey por meio da afirmação de que "exercemos controle sobre os objetos quando, deliberadamente e com sucesso, informados por nossas crenças sobre eles, os submetemos ao nosso poder e os utilizamos como meios tendo em vista nossos próprios fins" (Lacey, 1999, p. 111). Reconhecendo-a como parte da natureza humana, Lacey não critica a prática de controle dos objetos naturais per se, mas sim a supervalorização de que ela passa a ser objeto na modernidade. $\mathrm{O}$ alvo da crítica, em suas palavras, é

a extensão, a preeminência e a centralidade em nossas vidas [que a prática de controle adquire na época moderna], o valor elevado e virtualmente não subordinado concedido a ela, a dissociação das considerações sobre o controle das considerações relativas ao significado e ao valor de nossas atividades e arranjos sociais, os esforços intensos no sentido de expandir e implementar nossas capacidades de controle, e a convicção de que tais esforços estarão no cerne de projetos visando satisfazer nossas necessidades e desejos, mesmo quando sua realização dá origem continuamente a novas necessidades e desejos (Lacey, 1999, p. 111).

Na filosofia de Lacey, uma característica fundamental da ciência moderna consiste no fato de ela ser praticada quase exclusivamente de acordo com o que ele denomina estratégias materialistas, ou descontextualizadas, ${ }^{2}$ resultando tal característica das relações mutuamente reforçadoras que vigoram entre a adoção dessas estratégias e a supervalorização do controle da natureza. Sendo essa supervalorização um valor social, seu papel na escolha de estratégias implica a negação da tese da neutralidade da ciência. Porém, no presente contexto, o aspecto mais relevante do conceito de controle da natureza, tal como entendido por nosso autor, consiste por assim dizer no "outro" do controle, ou seja, nas posturas que não constituem formas de controle. Para Lacey,

O controle contrasta com posturas como a reciprocidade, a mutualidade e o respeito, de forma tal que o valor do objeto com o qual se interage reflete certa medida de integridade atribuída a ele, não se reduzindo ao valor instrumental para o agente. [...] A interação com a natureza pode ser circunscrita por seu ajuste com uma ordem social, ecológica ou cósmica, e por uma concepção particular de 
florescimento humano. Ela pode, por exemplo, em uma dada cultura, dar-se de acordo com os ritmos naturais, com um conjunto limitado de meios e fins definidos pela tradição, a qual garante, exceto em circunstâncias inesperadas, uma relação harmoniosa e recíproca com a natureza. Assim, o controle humano do ambiente natural é contrabalançado por seu sustento e manutenção, de maneira tal que as relações humanas dentro dele, e com ele, podem ser permanentes, e a preservação do ambiente impõe limites aos fins aceitáveis (Lacey, 1999, p. 111-2).

A caracterização do “outro" do controle adotada por Lacey pode à primeira vista, se pensado como alternativa para a cultura ocidental, dar a impressão de certa vagueza e de um caráter um tanto regressivo. Tal impressão é dissipada, entretanto, quando se consideram os rigorosos estudos que Lacey vem realizando nos últimos tempos a respeito das práticas de produção agrícola, questionando o uso de transgênicos e defendendo a agroecologia como alternativa mais satisfatória ao modelo tecnológico de agricultura, tanto do ponto de vista ecológico quanto do social e do econômico (cf. Lacey, 2005, 2006). Em sua defesa da agroecologia, as alternativas à postura de controle figuram de maneira muito mais precisa e isenta de qualquer traço regressivo ou obscurantista, entre outras razões porque na perspectiva agroecológica, os conhecimentos proporcionados pela ciência moderna, decorrentes da adoção da estratégia descontextualizada, mantêm um papel importante, ainda que subordinado.

Isso posto, podemos agora apresentar a idéia central do que propomos como sendo a contribuição deste trabalho. Trata-se da sugestão de um outro "outro" do controle, de outra prática que contrasta com a do controle da natureza - a saber, a prática do auto-controle. Todas as seções a seguir são dedicadas à elaboração dessa idéia. A linha de raciocínio a ser desenvolvida é bastante extensa, envolve algumas teses altamente controvertidas e, por isso, a exposição terá um caráter marcadamente esquemático. Seu objetivo consiste apenas em esboçar a estrutura lógica do raciocínio, indicando as tomadas de posição em relação às teses, sem a pretensão de demonstrá-las - o que seria na verdade uma pretensão enorme.

Em linhas gerais, vamos explorar o significado da adoção da postura de autocontrole tendo como pano de fundo os problemas ecológicos, primeiramente em uma perspectiva individual, em seguida, no nível das formas de organização social e, por fim, no domínio das práticas científicas. 


\section{Capitalismo, ecologia E AUTo-Gontrole individual}

O controle, ou dominação da natureza, tem uma relação muito evidente com os problemas ecológicos que a humanidade enfrenta; problema que nenhum dos críticos deixa de apontar (cf. Leiss, 1974, Introdução). De maneira mais ou menos direta, os problemas ecológicos decorrem da natureza finita do planeta em que vivemos ou, mais precisamente, das limitações da capacidade da Terra de prover os recursos naturais necessários para a realização das atividades econômicas humanas, e de absorver os resíduos dessas atividades. Tais limitações tornam-se ou não problemas dependendo do montante das atividades econômicas, ou seja, da quantidade de bens produzidos e consumidos, ou ainda, em termos da economia, das dimensões do Produto Interno Bruto, o famoso PIB. Ainda que a relação possa não ser linear, é perfeitamente razoável a premissa de que quanto maior o PIB, maior é a quantidade de recursos naturais consumidos e de resíduos gerados. ${ }^{3}$

Sendo assim, a solução que se apresenta para os problemas ecológicos consistiria em manter sob controle o montante das atividades econômicas. E, como tal montante é função do nível de consumo, e este depende das decisões dos consumidores, pode-se dizer que os problemas ecológicos estariam resolvidos se os consumidores decidissem manter seu nível de consumo em um âmbito compatível com as limitações do planeta. Tal raciocínio abstrato manifesta-se concretamente nas campanhas do movimento ambientalista visando conscientizar os cidadãos no sentido de serem evitados desperdícios no consumo dos bens materiais - de água, de energia elétrica, de combustíveis, de papel etc. - ou, de forma mais ampla, de serem adotadas práticas ecologicamente corretas.

3 Um marco no processo de tomada de consciência da incompatibilidade existente entre a perspectiva de um crescimento econômico ilimitado e o caráter finito do planeta Terra foi o relatório The limits to growth (Meadows et al., 1974), publicado originalmente em 1972 (cf. Furtado, 1974). Como alternativa ao crescimento ilimitado coloca-se naturalmente a perspectiva de um estado estacionário, de crescimento nulo do PIB (antecedido ou não por um período de decrescimento). Entre os autores, mencionados em The limits to growth, que tratam do tema, encontra-se J. S. Mill, cuja defesa do estado estacionário é notável por sua atualidade: "Não posso, portanto, considerar a condição estacionária do capital e da riqueza com essa aversão impassível manifestada pelos economistas da velha escola. Estou propenso a crer que essa condição estacionária seria, no conjunto, uma enorme melhoria de nossa condição atual. Confesso que não me encanta o ideal de vida defendido por aqueles que pensam que o estado normal dos seres humanos é aquele de sempre lutar para progredir do ponto de vista econômico, que pensam que o atropelar e pisar os outros, o dar cotoveladas, e um andar sempre ao encalço um do outro (características da vida social de hoje) são o destino mais desejável da espécie humana, quando na realidade não são outra coisa senão os sintomas desagradáveis de uma das fases do progresso industrial" (Mill, 1983, vol. II, p. 252). "Dificilmente será necessário observar que uma condição estacionária do capital e da população não implica uma condição estacionária do aperfeiçoamento humano. Haveria o mesmo campo que sempre há para todos os tipos de cultura intelectual, de progresso moral e social, o mesmo espaço para aperfeiçoar a arte de viver, e muito mais probabilidade desse aprimoramento ocorrer, se as inteligências deixassem de ser absorvidas exclusivamente pela preocupação de prosperar na riqueza" (p. 254). 
Neste primeiro nível, portanto, é evidente o significado da prática de auto-controle como alternativa à prática de controle da natureza. Em vez de procurar incrementar o controle da natureza para extrair dela cada vez mais recursos naturais, e maximizar sua capacidade de absorver resíduos, nós nos auto-controlamos racionalizando e restringindo nossos padrões de consumo.

Mas, dirá o crítico, será essa estratégia suficiente para superar os problemas ecológicos? Será possível restringir o consumo dessa forma, dependente da boa vontade dos indivíduos, em sociedades - como a de todos os países inseridos no processo de globalização - nos quais o crescimento do PIB tornou-se o valor supremo, nos quais toda a cultura está impregnada de valores consumistas e a publicidade trabalha incansavelmente para estimular, em vez de conter o consumo?

Chamemos de ambientalismo conservador o movimento que, reconhecendo a premência dos problemas ecológicos, sustenta que eles podem ser superados com um mínimo de alteração no sistema. Em sua resposta ao questionamento do crítico, o ambientalista conservador não abre mão do controle da natureza. Sem negar a validade das campanhas de conscientização dirigidas aos indivíduos, ele defende como principal a estratégia tecnológica de continuar incrementando as capacidades humanas de controle da natureza. Ou seja, a tese é a de que a saída para os problemas criados com a contribuição da tecnologia consiste em mais tecnologia - em tecnologias mais sofisticadas e poderosas.

Apesar do que possa parecer, a tese nada tem de auto-contraditória, e ganha plausibilidade por conta dos incontáveis sucessos da tecnologia, de sua capacidade demonstrada de tornar realidade idéias que, muitas vezes, pareciam só poder existir na fértil imaginação dos autores de ficção científica. Do ponto de vista da eficácia das inovações, é arriscado estabelecer de antemão limites ao que o empreendimento tecnológico pode realizar. É impossível, por exemplo, demonstrar cientificamente a impossibilidade de um avanço tecnológico que proporcione à humanidade uma fonte de energia abundante e cujo consumo seja isento de efeitos colaterais nefastos ao meio ambiente.

Porém, com o sentido oposto, de colocar em cheque a tese ambientalista conservadora, encontra-se um argumento bem conhecido e muito poderoso, o argumento das várias Terras - a saber, o argumento baseado no número de planetas iguais ao nosso que seriam necessários para prover os recursos naturais, e absorver os resíduos das atividades humanas, se toda a população do mundo tivesse o mesmo padrão de consumo que vigora em países como os Estados Unidos. As estimativas desse número variam bastante conforme as pressuposições e os modelos adotados para os cálculos. ${ }^{4}$

4. Um desses modelos é o que se baseia no conceito de pegada ecológica (ecological footprint). Cf. <http://www. footprintnetwork.org/>. 
Mas, mesmo tomando como premissa o número mínimo encontrado na literatura por volta de três -, o argumento não perde sua força. De fato, se, com base em princípios irrecusáveis de eqüidade e justiça social, rejeitarmos como inaceitável uma situação em que alguns países têm um nível de consumo várias vezes maior que o de outros, então, na ausência de uma redução global drástica, os problemas ecológicos adquirem uma dimensão avassaladora. 5 E, conseqüentemente, do ponto de vista do ambientalismo conservador, cresceria de tal forma a demanda por inovações necessárias para superar as limitações do planeta, que se tornaria mero wishful thinking a expectativa de que a tecnologia pudesse dar conta do recado.

Com isso, voltamos à estaca zero, ou seja, ao problema de como manter o nível de consumo global dentro dos limites compatíveis com as limitações da Terra. A questão colocada anteriormente era a de se isso seria possível nas sociedades modernas, levando em conta o peso da valorização do crescimento do PIB, dos valores consumistas e da publicidade. Reformulando a questão em termos mais abstratos, perguntemos agora: será que a limitação do crescimento econômico necessária para a superação dos problemas ecológicos é possível no contexto do sistema capitalista?

\section{Socialismo, Ecologia E AUTO-Gontrole SoGial}

Dado que a estratégia tecnológica é insuficiente, há uma forte razão para dar uma resposta negativa a essa questão. A razão consiste em que a valorização do crescimento econômico é decorrência necessária do que há de mais central na lógica do sistema capitalista. Assim como uma bicicleta que só se mantém em equilíbrio quando está em movimento, o capitalismo só pode funcionar satisfatoriamente com a economia em crescimento ou, em outras palavras, enquanto for mantido o processo de acumulação do capital, ou seja, o capitalismo é incompatível com o estado estacionário e mais ainda com o decrescimento. ${ }^{6}$ Essa constatação é consensual, afirmada com mais ênfase

\footnotetext{
5 É significativo que até recentemente o argumento das várias Terras ficava no terreno das idéias, em um registro hipotético. O extraordinário crescimento do PIB da China (e, em menor grau, da Índia) nos últimos anos, com o conseqüente aumento na demanda por recursos naturais, e seus impactos econômicos e ecológicos, resultou em uma mudança no status do argumento que, por assim dizer, passou do terreno das idéias para o da realidade concreta. 6 Curiosamente, em sua análise do capitalismo, Marx elabora um modelo de estado estacionário capitalista, o da "reprodução simples”, dedicando a ele um capítulo (xxi) do primeiro volume d'O capital (Marx, 1983). Nas palavras de um comentador, "é útil, e mesmo necessário para fins teóricos, imaginar um sistema capitalista que funciona ano após ano nos mesmos canais e sem mudanças. [Esse é o sistema da reprodução simples.] Isso permite compreender a estrutura de relações presentes no sistema como um todo da maneira mais clara e simples possível” (Sweezy, 1968, p. 75). Porém, como o autor se apressa em deixar claro, isso não significa que tal sistema possa existir concretamente: "Seguir esse procedimento não implica, entretanto, que jamais tenha havido ou possa haver um sistema que
} 
por algumas linhas de crítica ao capitalismo, mas aceita também por seus defensores. Prova disso é que, entre as propostas do ambientalismo conservador, não se encontra a de um capitalismo de crescimento zero e, menos ainda, de crescimento negativo. Em lugar dessa, a que figura com maior destaque é a do desenvolvimento sustentadoque implica em crescimento econômico e não dispensa, como um fator essencial, a estratégia tecnológica. ${ }^{7}$

Essas considerações teóricas, em um outro nível, se manifestam no fato de que, no curto prazo, um baixo crescimento do PIB ou, pior ainda, um crescimento nulo ou negativo, afeta a vida das pessoas de maneiras muito concretas e dolorosas, principalmente por seu impacto no nível de emprego. Como é natural, isso faz com que seja muito difícil destituir o crescimento econômico de seu status de valor supremo para as políticas econômicas, mesmo havendo fortes argumentos mostrando que, no médio e longo prazos, não podem ser senão desastrosas as conseqüências ecológicas dessa valorização. E sem esquecer que, já no presente, os danos causados ao meio ambiente prejudicam e muito a qualidade de vida de todos, especialmente, mas não exclusivamente, das camadas mais pobres das populações.

A tese da impossibilidade de superar os problemas ecológicos no contexto do sistema capitalista constitui o cerne do eco-socialismo - um movimento liderado por importantes intelectuais da França e dos Estados Unidos, e tendo muitos simpatizantes no Brasil. ${ }^{\mathbf{8}}$ Chamemos de socialismo clássico o ideário baseado nas contribuições de Marx e Engels que forneceu as diretrizes teóricas da revolução soviética, e de quase todas as outras revoluções socialistas do século xx. A primeira diferença entre os dois socialismos consiste na importância crucial atribuída pelo eco-socialismo à questão ecológica. A análise dessa diferença é um bom caminho para que se chegue a um entendimento correto das origens históricas e das forças que sustentam a valorização do crescimento econômico.

Na verdade, não são necessários estudos muito aprofundados sobre a história das idéias na modernidade para deixar claro que a valorização do crescimento econômico, independentemente de suas conexões com o capitalismo, é uma faceta, ou forma

permanece sempre igual ano após ano. Na verdade, quando examinamos a situação em que se supõe ausente a mudança, ficará claro que os elementos mais essenciais do capitalismo como ele realmente existe foram deliberadamente ignorados" (p. 75).

${ }_{7}$ Nos dias de hoje, existe na França um vigoroso movimento anti-capitalista que defende a tese do decrescimento, representado pelo Institut d'études économiques et sociales pour la décroissance (http://www.decroissance.org/ ?chemin=accueil) e, desde abril de 2006, por um partido, o PPLD, Parti pour la Décroissance (http://www.partipourla decroissance.net/).

8 Da literatura produzida pelo movimento, recomenda-se, como um texto introdutório, Löwy, 2005. Para uma exposição mais extensa do ideário eco-socialista, Kovel, 2002. 
de manifestação do ideal de progresso, que se instaurou tão solidamente no espírito da modernidade. Embora não restrito ao domínio da produção material, esse ideal de progresso coloca em primeiro plano a valorização dos avanços tecnológicos, ou seja, da expansão das capacidades humanas de controlar a natureza, como meio para permitir aos homens uma vida mais confortável, mais segura e rica. E foi tal o vigor que esse ideal adquiriu que, apesar de ter nascido e ter crescido junto com o capitalismo, o transcendeu, sendo incorporado também pelo socialismo clássico. O conceito marxista de desenvolvimento das forças produtivas, por um lado, não se distingue do amálgama do avanço tecnológico com o crescimento da economia, o qual constitui o cerne do ideal moderno de progresso. Por outro lado, como se sabe, é uma peça-chave da teoria marxista clássica, tanto na explicação das grandes mudanças históricas concebidas em termos de modos de produção, quanto como um valor a ser preservado no socialismo e no comunismo. Nessa visão, encapsulada na famosa passagem do prefácio da Contribuição à crítica da economia política, o socialismo constitui, na história da humanidade, um estágio superior ao do capitalismo por liberar para novos avanços o desenvolvimento das forças produtivas, que o capitalismo havia inicialmente impulsionado, passando depois a entravar. 9

No plano em que as idéias influenciam o curso da história, esse traço desenvolvimentista do socialismo clássico liga-se ao fato de o desempenho dos países comunistas do século passado ter sido, do ponto de vista ecológico, tão ou mais deletério que o dos países capitalistas.

Além de diferenças existem também, naturalmente, pontos em comum entre o socialismo clássico e o eco-socialismo. O mais fundamental consiste na concepção do capitalismo como um sistema em que a economia e, em outros planos, toda a vida social, é estruturada pela produção de mercadorias, sendo as atividades econômicas regu-

9 "Na produção social de sua existência, os homens entram em determinadas relações necessárias e independentes da sua vontade, relações de produção que correspondem a cada fase de desenvolvimento das suas forças produtivas materiais. O conjunto dessas relações de produção forma a estrutura econômica da sociedade, a base real sobre a qual se levanta a superestrutura jurídica e política e à qual correspondem determinadas formas de consciência social. [...] Ao chegar a uma determinada fase de desenvolvimento, as forças produtivas materiais da sociedade se chocam com as relações de produção existentes, ou, o que não é senão a sua expressão jurídica, com as relações de propriedade dentro das quais se desenvolveram até então. De formas de desenvolvimento das forças produtivas, estas relações convertem-se em obstáculos a elas. E abre-se, assim, uma época de revolução social. Ao mudar a base econômica, revoluciona-se, mais ou menos rapidamente, toda a imensa superestrutura erigida sobre ela. [...] Em linhas gerais podemos designar como outras tantas épocas de progresso, na formação econômica da sociedade, o modo de produção asiático, o antigo, o feudal e o moderno burguês. As relações burguesas de produção são a última forma antagônica do processo social de produção, antagônica, não no sentido de um antagonismo individual, mas de um antagonismo que provém das condições sociais de vida dos indivíduos. As forças produtivas, porém, que se desenvolvem no seio da sociedade burguesa criam, ao mesmo tempo, as condições materiais para a solução desse antagonismo. Com esta formação social se encerra, portanto, a pré-história da sociedade humana” (Marx, 1971, p. 20-2). 
ladas pelo mercado. O socialismo, em contraste, é a negação da mercadoria. Ele se instaura destruindo a base institucional da produção mercantil, ou seja, a propriedade privada dos meios de produção, e adotando uma forma racional de regulação das atividades econômicas, voltada para a produção de valores de uso e tendo por objetivo a satisfação equitativa das necessidades de toda a população.

Neste ponto, podemos estabelecer a conexão com a linha de raciocínio que vinha sendo desenvolvida, centrada na idéia de auto-controle. Usamos o termo "regulação" com referência às atividades econômicas porque este é o termo tradicionalmente usado pelos economistas quando se estuda, de um lado, o papel do mercado no sistema capitalista - como faz, por exemplo, Karl Polanyi (1980) em seu clássico A grande transformação -, de outro, o papel do planejamento central no sistema socialista. Mas está claro que, nesse contexto, regulação é sinônimo de controle e, assim, pode-se afirmar que, quando uma sociedade adota a forma racional de regulação das atividades econômicas própria do socialismo, ela está exercendo a prática de auto-controle, concebida não mais no plano do indivíduo, mas no plano social.

Do ponto de vista do socialismo, o sistema capitalista de regulação por meio do mercado aparece com um fenômeno curioso, em que um agente abdica voluntariamente da capacidade de decidir suas ações, para delegá-la a outra entidade, criada por ele, mas que se torna independente, passando a atuar como um déspota. Esse traço do mercado, de feitiço que virou contra o feiticeiro, nunca foi tão flagrante quanto na presente fase neoliberal do capitalismo, em que os meios de comunicação difundem continuamente a imagem antropomorfizada do mercado como um senhor todo-poderoso, exigente, volúvel, implacável com aqueles que desafiam suas leis.

No plano ideológico, essa servidão voluntária é justificada pelo argumento smithiano da mão invisível. Sejam quais forem os resultados do exame da validade do argumento no plano teórico, ele corresponde a uma tese que pode ser confrontada com dados empíricos, ou seja, com as conseqüências da experiência histórica da adoção do mercado como sistema regulador. Mesmo os mais ferrenhos defensores do capitalismo reconhecem que o mercado não é um sistema perfeito, admitindo a existência do que denominam falhas do mercado. Mas não serão tais falhas, no agregado, maiores que as vantagens, supostas ou reais, do sistema? Não são os problemas ecológicos, pelo menos em parte, conseqüências de uma enorme falha do mercado?

Sendo aceita a tese de que os problemas ecológicos não podem ser superados no contexto do capitalismo, e admitindo-se, primeiro, que o modelo soviético, que vigorou nos países comunistas do século xx, não constituia um sistema capitalista, no sentido em que suas economias não eram reguladas pelo mercado; segundo, que seu desempenho do ponto de vista ecológico foi igual ou pior que o dos países capitalistas, a conclusão a que se chega é a de que a negação do capitalismo é uma condição necessária 
mas não suficiente para a superação dos problemas ecológicos. Necessária, para tirar o controle das atividades econômicas das mãos do mercado, permitindo que as sociedades se auto-controlem em sua vida econômica. Insuficiente, porque tal forma de controle só atingirá os objetivos almejados, se for norteada por valores independentes dos de crescimento econômico e de expansão do controle da natureza, que o socialismo clássico e o modelo soviético compartilhavam com o capitalismo.

\section{Auto-GONTRole E AUTONOMIA DA GiÊNGIA}

Passemos agora à última etapa de nosso argumento, que nos leva de volta à tese da neutralidade da ciência. A pergunta que se apresenta como ponto de partida é: terá o conceito de auto-controle alguma relevância em uma reflexão sobre a tese da neutralidade? Assim como no caso da economia, na qual se identificou "regulação" com "controle", a resposta aqui também passa pelo reconhecimento de uma sinonímia bem clara, a saber, a do auto-controle com a autonomia - sendo a autonomia um tema tradicional nos discursos sobre a ciência, diretamente ligado ao da neutralidade.

Diz-se que a ciência é autônoma quando as decisões, que determinam seu modo de ser e de desenvolver-se, são tomadas pela própria comunidade científica, com base em seus valores internos - o valor fundamental do conhecimento como um fim em si mesmo, e os valores mobilizados na escolha entre teorias (na terminologia de Lacey, os valores cognitivos). Na concepção ortodoxa da ciência, todos esses valores são pensados como universais e perenes, superiores assim aos valores sociais, variáveis segundo as culturas e ao longo do tempo. Em termos mais concretos, a autonomia constitui a reivindicação de que a prática científica não sofra interferências externas, de natureza religiosa, política ou ideológica.

Em colaboração com Pablo Mariconda, Lacey escreveu um excelente artigo, intitulado "A águia e os estorninhos: Galileu e a autonomia da ciência" (Lacey \& Mariconda, 2001), onde se mostra como a reivindicação de autonomia nasce junto com a própria ciência moderna, figurando no cerne da disputa de Galileu com a Igreja católica e o establishment acadêmico. Fica patente ao longo do artigo a enorme importância de Galileu como um dos pensadores que mais contribuíram para o processo de desencantamento do mundo e para o estabelecimento da concepção da ciência livre de valores. Como dizem Lacey e Mariconda:

O símbolo de Galileu no conflito com a Igreja nutriu a idéia de que a ciência é ou deve ser livre de valores, permitindo que essa idéia ganhasse seu lugar como uma parte, reiteradamente afirmada e freqüentemente reinterpretada, do auto- 
entendimento comum da tradição científica moderna. Mas, quando se discute a liberdade da pesquisa científica, Galileu é muito mais que um símbolo; seus argumentos em favor da autonomia da ciência são seminais (Lacey \& Mariconda, 2001, p. 51).

E qual a natureza da argumentação de Galileu? Segundo os autores,

A estratégia de Galileu é [...] a de desenvolver um argumento tão efetivo quanto correto; ou seja, um argumento capaz de persuadir as autoridades religiosas. Qualquer argumento efetivo de que a ciência deve estar livre da interferência da Igreja não poderia permitir que o empreendimento científico estivesse sujeito a restrições por parte de setores opostos à Igreja católica. Galileu é levado, então, a argumentar que a ciência deve estar livre de todas as interferências de fora (externas) ao mesmo tempo que se obriga a retratá-la como um "valor universal”, um objeto de valor para qualquer ponto de vista moral ou metafísico razoável.

$\mathrm{O}$ argumento de Galileu - refinado, generalizado e suplementado - permanece no centro de todas as defesas da autonomia da ciência (Lacey \& Mariconda, 2001, p. $5^{2}$.

Essa passagem traz à tona o aspecto essencial da relação entre a autonomia e a neutralidade da ciência. A partir da generalização do argumento de Galileu, podemos dizer que, para exigir que se mantenha livre de cada tipo determinado de interferência, a ciência precisa alegar que é livre de quaisquer outros tipos. Estar livre de interferências externas significa estar livre de valores sociais, ou, seja, ser neutra. Assim, a neutralidade é a base em que se assenta a reivindicação de autonomia. Mais precisamente: a alegação de que a ciência é, real ou potencialmente, neutra serve para legitimar a reivindicação de que ela deve ser autônoma - deve ser autônoma exatamente para que possa tornar-se ou continuar a ser neutra.

Consideremos agora a pergunta: será que a comunidade científica teve sucesso em sua reivindicação de autonomia? Será a ciência hoje em dia autônoma? A resposta que vamos propor é negativa, e assenta-se em estudos realizados há um certo tempo, cujos resultados foram expostos principalmente em dois artigos, a saber, "Desmercantilizar a tecnociência" (Oliveira, 2004) e "Ciência: força produtiva ou mercadoria?" (Oliveira, 2005). Muito resumidamente, nesses artigos procuro mostrar, de diferentes pontos de vista, que ao longo dos últimos cento e tantos anos a ciência vem passando por um duplo processo de transformação, que se acentua na presente etapa neoliberal do capitalismo. 
Para descrever esses processos, convém introduzir explicitamente o par de conceitos formado pelo valor intrínseco e o valor instrumental, pensados com relação à ciência. O valor intrínseco é o valor do conhecimento como um fim em si mesmo, que figura na tese de neutralidade temática como razão de ser da ciência, e corresponde ao ideal da ciência pura. O valor instrumental é o valor da ciência como geradora de tecnologias, ou seja, como meio para incrementar a capacidade humana de controle da natureza. É importante observar que a sustentação da tese da neutralidade temática não implica a desconsideração do valor instrumental. A concepção ortodoxa da ciência, especialmente tal como articulada pelos positivistas lógicos, reconhece e atribui importância às aplicações da ciência, porém como um valor subordinado, um subproduto ou bônus resultante da busca do conhecimento como um fim em si mesmo (cf. Oliveira \& Fernandez, 2007, p. 70-1).

O primeiro processo pelo qual passa a ciência é o de tecnologização. A tecnologização consiste em uma mudança no peso relativo dos dois valores da ciência, no crescimento do valor instrumental em detrimento do valor intrínseco. Em termos mais simples, o conhecimento científico é valorizado cada vez mais por seu poder de gerar tecnologias, cada vez menos como um fim em si mesmo. O processo de tecnologização da ciência é um aspecto da supervalorização da prática de controle característica da modernidade, atuando tanto no sistema capitalista quanto no sistema dos países comunistas do século xx. Ele tende a fortalecer os vínculos entre a ciência e a tecnologia, dando origem ao amálgama que passou a ser chamado de tecnociência - um neologismo surgido, não por acaso, no presente período neoliberal, como um sintoma da intensificação do processo de tecnologização que nele ocorre. Levado a seu limite, o processo implica a morte da ciência pura.

O segundo processo, exclusivo do capitalismo, é o da mercantilização. O tema da mercantilização está muito presente no debate contemporâneo, em que se defende e se critica a mercantilização da educação, da cultura, do esporte, das sementes e de inúmeros outros bens ou práticas sociais. A mercantilização da ciência é parte do processo mais amplo de mercantilização universal, ligando-se estreitamente, por um lado, à mercantilização da universidade, por outro, à mercantilização da tecnologia, na qual o sistema de patentes desempenha um papel crucial. É um processo bastante complexo, que envolve inúmeras facetas, tais como: as avaliações de natureza quantitativa a que são submetidos os pesquisadores e instituições de pesquisa; a contenção das verbas estatais destinadas às universidades públicas; as pressões no sentido de que essa contenção seja compensada pela conquista de fontes alternativas de fundos junto à iniciativa privada; o estímulo à obtenção de patentes por parte dos pesquisadores nas universidades e instituições públicas de pesquisa; a proliferação e crescente importância 
das fundações de apoio etc. Mas, para nossos propósitos - que incluem o de deixar clara a relação entre os processos de tecnologização e mercantilização -, convém concentrar o foco nos critérios utilizados pelas agências de fomento no julgamento de pedidos de auxílio financeiro para a realização de projetos de pesquisa. Pode-se dizer que esses critérios correspondem, neste nível mais concreto, aos valores envolvidos na escolha dos temas e problemas a serem investigados pela ciência, tais como figuram na formulação da tese da neutralidade temática.

Nesse contexto, a tecnologização da ciência se expressa como o aumento do peso relativo atribuído à capacidade de gerar aplicações, mais precisamente, aplicações úteis, no sentido de que trazem algum benefício para a humanidade. O processo de mercantilização altera a forma desse quesito: o que passa a ser exigido de um projeto é que leve não a aplicações úteis, mas a aplicações rentáveis. Se o projeto prometer aplicações rentáveis, embora inúteis, isso não é motivo para uma resposta negativa à solicitação. Resposta negativa recebe, no caso inverso, o projeto que promete aplicações úteis mas não rentáveis. ${ }^{10}$ Mas, de maneira geral, para funcionar como mercadoria, ou seja, para ter valor de troca, um bem precisa ter um valor de uso e, assim, podemos dizer que, no capitalismo, o processo de tecnologização da ciência é impulsionado pelo de mercantilização.

Na ciência mercantilizada, portanto, o critério fundamental na avaliação de projetos é a rentabilidade - um valor social, externo à ciência, e não o valor interno do conhecimento como um fim em si mesmo. Ora, quem determina o que é e o que não é rentável é o mercado e, desse modo, conclui-se que, com a mercantilização, os destinos da ciência ficam nas mãos do mercado. E nessa medida - respondendo agora à pergunta em pauta - a ciência, qualquer que tenha sido sua situação no passado, deixa de ser autônoma. Tal conclusão, na verdade, corresponde apenas à extensão do mercado como princípio regulador ao caso da ciência. A mercantilização, dessa perspectiva, aparece como um meio de submeter a ciência ao controle do mercado, sendo mais uma manifestação da tendência capitalista a transformar tudo em mercadoria, que se acentua no neoliberalismo.

10 No campo da pesquisa médica (incluindo a pesquisa feita nas indústrias farmacêuticas), um exemplo do primeiro caso são as pesquisas direcionadas para a criação de medicamentos "eu também" (me too drugs). Medicamento "eu também” é aquele criado para substituir no mercado um medicamento já existente, porém com patente cujo prazo de validade terminou ou está em vias de terminar, sem oferecer vantagem alguma (e às vezes com desvantagens) em relação a este (cf. Angell, 2007, Cap. 5). Exemplo do segundo caso é o relacionado às doenças negligenciadas - as que afetam primordialmente as populações pobres do mundo, sendo entretanto pouco contempladas com pesquisas cujos resultados, tendo em vista o baixo poder aquisitivo dessas populações, têm baixo potencial de gerar lucros (cf. o dossiê "Outlook: neglected diseases" da revista Nature, 449, 7159, p. 157-82, 13 de setembro de 2007). 
Parece então que se chegou a um impasse. Havíamos identificado o auto-controle com a autonomia; se a autonomia é uma ilusão, então aparentemente não existe um papel positivo para o auto-controle desempenhar no que se refere à ciência. Haverá uma saída?

Sim, a saída consiste em perceber que a reivindicação posta pela comunidade científica desde Galileu não foi simplesmente uma reivindicação de autonomia: foi a reivindicação de um tipo particular de autonomia - o tipo que recorre para sua legitimação à tese da neutralidade da ciência. Além de sua função legitimadora, por um lado, da reivindicação de autonomia, por outro, da postura de dominação da natureza, a tese da neutralidade serve também - como indicamos no início - para colocar a ciência fora do alcance de questionamentos em termos de valores sociais e para atribuirlhe um valor universal, de tal forma que qualquer cultura que não a incorpora é ipso facto considerada inferior à cultura ocidental. Quando se toma distância do cientificismo reinante no Ocidente, não se pode deixar de perceber o quanto de pretensão, arrogância e mesmo prepotência existe nessa forma de autonomia baseada na neutralidade. Embora tenha tido uma função histórica positiva, contribuindo para libertar a ciência da autoridade da Igreja, e de outras interferências externas nefastas, ela é hoje inaceitável para os setores mais esclarecidos da sociedade.

É inaceitável, primeiro, para todos aqueles que propõem formas alternativas de relacionamento do homem com a natureza - nos moldes, por exemplo, do "outro" do controle caracterizado por Lacey -, que acreditam na existência de formas viáveis e desejáveis de re-encantamento do mundo. É inaceitável também para todos os que, embora reconhecendo as incontáveis contribuições da ciência para o bem-estar das populações na civilização ocidental, julgam que o impacto da ciência na sociedade está longe de ser inteira e inequivocamente benéfico, que a ciência deve sim ser submetida a questionamentos em termos de valor e, em um espírito democrático, que o ritmo e os rumos da pesquisa científica devem ser objeto de um debate do qual participa toda a sociedade. E é inaceitável por quem preza a diversidade cultural, defendendo o direito das culturas não ocidentais de existirem e serem respeitadas, e opondo resistência à homogeneização promovida pela globalização neoliberal.

E haverá alguma forma de autonomia que possa ser legitimamente reivindicada? Sim; é a forma que tem como paradigma a autonomia do cidadão emancipado em uma sociedade emancipada. Não a autonomia arrogante, de um ser que se coloca acima dos outros, mas a autonomia do indivíduo vivendo em sociedade com outros indivíduos também autônomos. Vivendo em permanente diálogo com seus semelhantes, sendo esta relação constitutiva de seu ser. É a forma de autonomia que valoriza a individualidade, associada ao respeito pela diferença e à preocupação com o bem de todos. 
Aplicada à ciência, o que significa essa concepção? Significa uma ciência que se coloca não acima, mas ao lado de outras instituições e outras formas de conhecimento - incluindo as tradicionais. Uma ciência senhora de seu destino, mas que toma suas decisões a partir de um diálogo com outros setores da sociedade, com outras visões de mundo. Uma ciência que dá ouvidos às críticas sérias que lhe são dirigidas em vez de rejeitá-las in limine como retrógradas, obscurantistas, carentes de racionalidade. Uma ciência que, no ambiente acadêmico, não olha para as humanidades e as artes com desdém, não age como um poder imperialista, impondo a toda a universidade as formas de sua prática, seus métodos e seus critérios de avaliação. Uma ciência capaz de auto-crítica, e capaz de perceber que toda crítica, no sentido pleno do termo, envolve valores sociais, não podendo ser conduzida no universo conceitual da ciência desencantada. Uma ciência afinada não com a postura de controle, mas com a de auto-controle, nas relações da humanidade com a natureza.

O movimento em direção a uma ciência que reivindica sua autonomia nessas bases implica naturalmente mudanças profundas nas práticas científicas e no estilo de vida dos cientistas. Tendo a comunidade científica que dedicar uma parte de seu tempo e energia à reflexão sobre seu papel na sociedade, o resultado não pode deixar de ser uma diminuição no ritmo de progresso da ciência, segundo os parâmetros com que tal progresso é hoje avaliado. Talvez os cientistas achem esse um preço muito alto a ser pago. Cabe então deixar claro que o preço é de fato alto, mas compensador, que só dessa forma a ciência poderá recuperar seu prestígio, passando a contribuir de forma mais positiva para a sociedade, só dessa forma poderá recobrar a dignidade perdida ao se submeter servilmente aos interesses do mercado.

\author{
Marcos Barbosa de Oliveira \\ Professor Doutor da Faculdade de Educação da \\ Universidade de São Paulo, Brasil. \\ mbdolive@usp.br
}




\begin{abstract}
AB STRACT
The aim of this essay is to investigate self-control as an alternative to the practices of control, or domination of nature, in the context of ecological problems, first by individuals, then by society, and finally, by science. The starting point is an analysis of the thesis of the neutrality of science into three components, one of which - the thesis of factual neutrality - reflects the descriptive character of scientific propositions, and is strongly linked to the control of nature. The high value attributed to the control of nature characteristic of modernity is in turn seen as one of the causes of ecological problems. In order to overcome those problems, it is argued that the adoption of practices of self-control is needed, not only by individuals, but also, and more crucially, by society, and that social self-control is incompatible with the dynamics of the capitalist system. In the final section, self-control in the domain of science is identified with autonomy, and it is shown that the traditional claim of autonomy, made on the basis of neutrality, is no longer tenable, given the processes of commodification to which science is subjected to. To conclude, an alternative kind of autonomy is suggested, in which science is placed not above, but at the side of other forms of knowledge and other social institutions.
\end{abstract}

KEYWORDS $\bullet$ Neutrality. Disenchantment of the world. Control of nature.

Domination of nature. Ecosocialism. Self-control. Autonomy. Lacey.

\title{
REFERÊNGIAS BIBLIOGRÁFIGAS
}

Angell, M A. Verdade sobre os laboratórios farmacêuticos : como somos enganados e o que podemos fazer a respeito. Rio de Janeiro: Record, 2007.

Furtado, C. O mito do desenvolvimento econômico. Rio de Janeiro: Paz e Terra, 1974.

Global Footprint Network. <http://www.footprintnetwork.org/>. Acessado em 20/o7/2008.

Institut d'Études Économiques et Sociales pour la Décroissance Soutenable. <http://www.decroissance. org/?chemin=accueil>. Acessado em 20/07/2008.

Kovel, J. The enemy of nature: the end of capitalism or the end of the world? New York: Zed Books, 2002.

LACEY, H. Is science value free?: values and scientific understanding. London/New York: Routledge, 1999. .Values and objectivity in science and the current controversy about transgenic crops. Lanham: Lexington Books, 2005 . A controvérsia sobre os transgênicos. Questões científicas e éticas. Aparecida: Idéias e Letras, 2006.

LAcey, H. \& Mariconda, P. R. Aáguia e os estorninhos: Galileu e a autonomia da ciência. Tempo Social, 13, 1, p. $49-65,2001$.

Leiss, W. The domination of nature. Boston: Beacon Press, 1974 .

Löwr, M. Ecologia e socialismo. São Paulo: Cortez, 2005.

MARX, K. A contribution to the critique of political economy. London: Lawrence \& Wishart, 1971. . Grundrisse. Harmondsworth: Penguin, 1973. . O capital: crítica da economia política. São Paulo: Abril Cultural, 1983.

Meadows, D. et al. The limits to growth. London: Pan Books, 1974.

Mill, J. S. Princípios de economia política, com algumas de suas aplicações à filosofia social. São Paulo: Abril Cultural, 1983.

Oliveira, M. B. Desmercantilizar a tecnociência. In: Santos, B. de S. (Org.). Conhecimento prudente para uma vida decente. "Um discurso sobre as ciências" revisitado. São Paulo: Cortez, 2004. p. 241-66. . Ciência: força produtiva ou mercadoria? Crítica Marxista, 21, p. 77-96, 2005. 
Oliveira, M. B. \& Fernandez, B. P. M. Hempel, Semmelweis e a verdadeira tragédia da febre puerperal. Scientiae Studia, 5, 1, p. 49-79, 2007.

PARTi pour la Décroissance. <http://www. partipourladecroissance.net/>. Acessado em 20/o7/2008.

Pierucci, A. F. O desencantamento do mundo: todos os passos do conceito em Max Weber. São Paulo: 34, 2003.

Polanyi, K. A grande transformação. Rio de Janeiro: Campus, 1980.

Santos, B. de S. (Org.). Conhecimento prudente para uma vida decente. "Um discurso sobre as ciências" revisitado. São Paulo: Cortez, 2004.

SweEzy, P. The theory of capitalist development: principles of Marxian political economy. New York: Monthly Review Press, 1968. 